\title{
Do neurologists in Germany adhere to the national Parkinson's disease guideline?
}

\author{
This article was published in the following Dove Press journal: \\ Neuropsychiatric Disease and Treatment \\ 4 March 2011 \\ Number of times this article has been viewed
}

\author{
Sabrina Schröder ${ }^{\prime}$ \\ Daniel Kuessner ${ }^{2}$ \\ Guy Arnold ${ }^{3}$ \\ York Zöllner ${ }^{4}$ \\ Eddie Jones ${ }^{5}$ \\ Marion Schaefer' \\ Institute of Clinical Pharmacology, \\ Charité University Medicine, \\ CCM, Berlin, Germany; ${ }^{2}$ Basilea \\ Pharmaceutica, Basel, Switzerland; \\ ${ }^{3}$ Department of Neurology, \\ Sindelfingen-Böblingen Hospital, \\ Sindelfingen, Germany; ${ }^{4}$ Mapi Values, \\ Houten, The Netherlands; ${ }^{5}$ Adelphi \\ Group Products, Macclesfield, UK
}

Correspondence: Sabrina Schröder Charité University Medicine, Institute of Clinical Pharmacology, CCM Invalidenstrasse II5, D-I0II5

Berlin, Germany

Tel +49 I 702167876

Fax +4930945 10 14।

Email sabrina.schroeder@charite.de

\begin{abstract}
Implementation of guidelines can improve clinical practice. The aim in this study was to investigate whether neurologists in Germany adhered to the national Parkinson's disease guideline. Data were obtained from a cross-sectional survey of 60 neurologists. Analyses were performed on 320 patients with idiopathic Parkinson's disease with either low grades of functional impairment (Hoehn and Yahr stage I) or higher grades of functional impairment (stage II-V) but without motor complications. The sample was divided into four groups depending on age and grade of functional impairment. For each group, a biometric parameter on the use of dopamine agonists and L-dopa was defined based on the guideline. In patients aged $<70$ years, the recommendation to use dopamine agonists without L-dopa (parameter 1) was observed in 53\% of patients with lower grades of functional impairment, whilst recommended use of dopamine agonists in more functionally impaired patients (parameter 2) was followed to a greater extent (84\%). In patients aged $\geq 70$ years, recommendations to use L-dopa without dopamine agonists were adhered to in only $50 \%$ of less functionally impaired (parameter 3 ) and $52 \%$ of more functionally impaired (parameter 4) patients. In conclusion, our results indicated there was moderate but not full adherence to the guideline.
\end{abstract}

Keywords: Parkinson's disease, dopamine agonists, L-dopa, neurologists, national guideline, Germany

Although there is currently no cure for Parkinson's disease, a number of treatments exist that can ameliorate symptoms, improve quality of life, and help avoid secondary complications. ${ }^{1}$ Unfortunately, the therapeutic effect of one of the mainstays of treatment, L-dopa, declines after several years of use and patients may develop latestage motor complications ${ }^{2}$ that greatly impact on their quality of life. ${ }^{3}$ These can be either hypokinetic (eg, "wearing off", end-of-dose effect, dystonia) or hyperkinetic (eg, peak-dose dyskinesia, biphasic dyskinesia). The attempt to return patients to a certain degree of autonomy in mobility in their professional and daily life, especially in the later stages of the disease, continues to be a medical challenge associated with a heavy economic burden. ${ }^{4-6}$

The prevalence of Parkinson's disease in Germany is approximately 150 cases per 100,000 inhabitants and 1,800 cases per 100,000 among people aged over 65 years. ${ }^{7}$ Germany therefore has the largest number of prevalent cases of Parkinson's disease of any country in Europe. In 2003, the Competence Network on Parkinson's disease (CNP), a German national network supported by the Federal Ministry of Education and Research, developed its first guideline on Parkinson's disease according to the recommendations of the German Instrument for Methodological Guideline Appraisal. 
The German Society for Neurology then published the first national guideline for the treatment of Parkinson's disease (status as of 11.06.2003) $)^{8}$ based on international standards. ${ }^{9-11}$ Germany was one of the first European countries to publish national guidelines as treatment standards for physicians in the area of Parkinson's disease. At the same time, changes in health reforms within Germany that increased demand for higher quality and more cost-effective treatment regimes ${ }^{12}$ also had an impact on physicians' prescribing behaviors and may have influenced whether or not they followed the new guideline.

Germany was therefore chosen from a multinational survey to evaluate the awareness and knowledge of the German practice guideline for Parkinson's disease among neurologists. The national guideline's treatment recommendations were based on the following core principles that were aimed at delaying the onset of late-stage complications and reducing side effects: 1) patients less than 70 years old should be treated with dopamine agonists without L-dopa (L-dopa sparing approach); 2) if required for stable and adequate symptom control, more impaired patients less than 70 years old may use L-dopa in addition to dopamine agonist based treatment; 3) older patients and those with comorbid conditions should receive L-dopa, whilst the use of dopamine agonists should be avoided until motor complications occur; 4) independent of age and treatment basis, monotherapy should be initiated and maintained for as long as possible until patients' impairment requires more complex treatment.

If this standard is followed, individualized pharmacotherapy based on age, disease stage, and characteristics can result in an improved ongoing relief from symptoms and may delay the onset of long-term motor complications. Hence, guidelines issued by national professional societies are of particular practical relevance for treating physicians although, to date, little information is available on whether or not physicians adhere to these guidelines and implement them in their daily practice. ${ }^{13-16}$ The objective of this study was therefore to investigate whether neurologists in Germany implement the Parkinson's disease national guideline in their daily practice, as exemplified by the actual use of dopamine agonists and L-dopa as recommended by the German Society for Neurology.

\section{Method}

\section{Data collection}

Germany was chosen as part of a multinational, crosssectional survey that was conducted amongst neurologists treating patients suffering from Parkinson's disease (Adelphi
Group Products. Parkinson's II Disease Specific Programmes: Real World Studies. Data on file. Macclesfield, UK. 2004). ${ }^{17}$ Data was collected during QII (April-June) 2004 from a total of 60 neurologists who were recruited in Germany. In order to cover all German regions equally, nationally representative samples of specialists who were responsible for decisions regarding drug therapy and management of outpatients with Parkinson's disease were randomly screened using telephone interviews. Only those who expected to complete at least 10 patient records during a 2 week period were recruited; they were then asked to complete patient record forms for the next 10 Parkinson's disease patients that visited their practice. The details recorded included demographics, symptoms and functionality, Hoehn and Yahr (H\&Y) stage, consultation history, and drug therapy. The study was conducted in accordance with ESOMAR guidelines ${ }^{18}$ and ethical approval from the institutional review board was not required.

The 60 neurologists provided data on 608 patients with Parkinsonism, of whom the 451 with a diagnosis of idiopathic Parkinson's disease (according to the UK Brain Bank Criteria) ${ }^{19}$ were taken into consideration for further analyses. These figures are consistent with Parkinsonism and Parkinson's disease diagnosis in a community based sample of participants. ${ }^{20}$ Patients were divided into five grades according to their level of functional impairment as rated by the physicians: patients without functional impairment (grade I), patients in H\&Y stage I (grade II), patients in H\&Y stage II-V without motor complications (grade III), patients with motor complications (grade IV), and patients in the palliative phase (grade V). Motor complications were defined as L-dopa-associated such as dyskinesia, dystonia, on-off fluctuations, and $>10 \%$ off time per day. Explicit rules to test guideline adherence, however, could only be derived for patients receiving drug treatment who were without motor complications. This selection was mandatory due to the complexity of treatment regimes in patients with L-dopa-associated motor complications, thus making the rules otherwise difficult to specify. Consequently, only the 320 patients in grade II $(n=82)$ and grade III $(n=238)$ were included in the final analyses. The patients were also divided into those aged $<70$ years $(n=191)$ and those aged $\geq 70$ years $(n=129)$.

\section{Assessment of guideline adherence Adherence to the national guideline was assessed using a number of methods}

Firstly, we defined four explicit parameters regarding the use of dopamine agonists and L-dopa that reflect the guideline's 
recommendation based on the four core principles. These parameters were used to perform precise biometric analyses to quantify the qualitative principle of the guidelines (Table 1).

The parameters were:

- Parameter 1. Patients aged $<70$ years old in grade II: use of dopamine agonist without L-dopa (L-dopa sparing approach)

- Parameter 2. Patients aged $<70$ years old in grade III: use of any dopamine agonist as mono- or combination therapy

- Parameter 3. Patients aged $\geq 70$ years old in grade II: use of L-dopa without dopamine agonists

- Parameter 4. Patients aged $\geq 70$ years old in grade III: use of L-dopa without dopamine agonists

Hence, for each patient selected for the analyses, one of the four parameters was applicable depending on age and grade of functional impairment. The percentage agreement between the patient's treatment and the applicable parameter was therefore selected as the key outcome parameter in the main analysis.

Secondly, adherence to the parameters was compared within two groups of patients classified according to the claimed guideline adherence by the neurologist: "guideline group" (patients treated according to the national guideline as stated by their neurologists) and the "nonguideline group" (patients not treated according to the national guideline as stated by their neurologists). Chi-square tests for contingency tables were performed to investigate the relative agreement between the guideline and nonguideline groups. If the requirements were not met, Fisher's exact test was used. The probability criterion for rejecting the null hypotheses was $P=0.05$.

Thirdly, further subgroup analyses were performed focusing on symptom severity, time since diagnosis, and the presence of cognitive impairment/dementia. Since recommendations for treatment initiation differ in patients with mild symptoms, drug use was analyzed according to physician-rated symptom severity (presence/absence of mild symptoms of tremor at rest, rigidity, and bradykinesia) in patients in grade II. Assuming that disease duration may influence therapy in more functionally impaired patients, drug use was also analyzed based on time since diagnosis $(<5$ years versus $\geq 5$ years) in patients in grade III. The division was made at 5 years since many patients begin to notice a decline in benefit after about 5 years of dopaminergic therapy. ${ }^{21}$

Finally, prompted by one of the guideline's core recommendations on the "reluctant use of dopamine agonists in patients with active comorbid medical problems", drug use was analyzed in patients in grades II and III according to the presence/absence of cognitive impairment as a symptom and/or dementia as a diagnosis, as rated by the physicians according to their clinical standards.

All statistical analyses were performed using STATA software (Version 9.1; Stata Corporation, College Station, TX).

\section{Results}

Of the 60 neurologists, 54 were office-based, five hospitalbased, and one was based in both an office and a hospital.

Table I Translation of German national guideline into explicit parameters in idiopathic Parkinson's disease $(n=45 \mathrm{I})$

\begin{tabular}{|c|c|c|c|c|c|c|}
\hline & & $\begin{array}{l}\text { Without } \\
\text { functional } \\
\text { impairment } \\
\text { (Grade I) }\end{array}$ & $\begin{array}{l}\text { Lower grade of functional } \\
\text { impairment without } \\
\text { motor fluctuations or } \\
\text { complications (Grade II) }\end{array}$ & $\begin{array}{l}\text { Higher grade of functional } \\
\text { impairment without motor } \\
\text { fluctuations or complications } \\
\text { (Grade III) }\end{array}$ & $\begin{array}{l}\text { L-dopa associated } \\
\text { motor fluctuations } \\
\text { or complications } \\
\text { (Grade IV) }\end{array}$ & $\begin{array}{l}\text { Palliative } \\
\text { phase } \\
\text { (Grade V) }\end{array}$ \\
\hline \multirow[t]{3}{*}{$\begin{array}{l}<70 \text { years } \\
(n=25 I)\end{array}$} & $\begin{array}{l}\text { Standard } \\
\text { treatment }\end{array}$ & & $\begin{array}{l}\text { DA (monotherapy) } \\
\text { Parameter I: \% DA } \\
\text { without L-dopa }\end{array}$ & $\begin{array}{l}\text { DA (mono or combination } \\
\text { therapy) } \\
\text { Parameter } 2: \% \text { DA }\end{array}$ & \multirow{2}{*}{\multicolumn{2}{|c|}{$\begin{array}{l}\text { Complex management (depending } \\
\text { on types of motor fluctuations and } \\
\text { complications) }\end{array}$}} \\
\hline & $\begin{array}{l}\text { Alternative } \\
\text { treatment }\end{array}$ & & $\begin{array}{l}\text { L-dopa (if risk of losing job), } \\
\text { amantadine/selegiline (if mild } \\
\text { symptoms) }\end{array}$ & & & \\
\hline & Patients & $n=5(2.0 \%)$ & $n=64(25.5 \%)$ & $n=127(50.6 \%)$ & $n=53(21.1 \%)$ & $\mathrm{n}=2(0.8 \%)$ \\
\hline \multirow[t]{3}{*}{$\begin{array}{l}\geq 70 \text { years } \\
(n=200)\end{array}$} & $\begin{array}{l}\text { Standard } \\
\text { treatment }\end{array}$ & & $\begin{array}{l}\text { L-dopa (monotherapy) } \\
\text { Parameter 3: \% L-dopa } \\
\text { without DA }\end{array}$ & $\begin{array}{l}\text { L-dopa (monotherapy) } \\
\text { Parameter 4: \% L-dopa } \\
\text { without DA }\end{array}$ & $\begin{array}{l}\text { Complex management } \\
\text { (depending on types of } \\
\text { fluctuations and compli }\end{array}$ & $\begin{array}{l}\text { motor } \\
\text { ations) }\end{array}$ \\
\hline & $\begin{array}{l}\text { Alternative } \\
\text { treatment }\end{array}$ & & $\begin{array}{l}\text { amantadine/selegiline } \\
\text { (if mild symptoms) }\end{array}$ & & & \\
\hline & Patients & $\mathrm{n}=\mathrm{I}(0.5 \%)$ & $\mathrm{n}=18(9.0 \%)$ & $\mathrm{n}=\mathrm{I} \mathrm{I}(55.5 \%)$ & $n=60(30.0 \%)$ & $\mathrm{n}=10(5.0 \%)$ \\
\hline
\end{tabular}

Note: Shaded area: patients included in analysis.

Abbreviation: DA, dopamine agonist. 
The mean number of Parkinson's disease patients seen per week was 20.2 (range 14-25). The neurologists had a wide range of length of experience: $23 \%$ had been qualified for 9-14 years, 37\% for 15-24 years, and 30\% for 25-34 years. All reported that they were aware of the content of the national treatment guidelines on Parkinson's disease. The demographic characteristics of the 320 patients in grade II $(\mathrm{n}=82 ; 56 \%$ male; mean age 63.4 years) and III $(\mathrm{n}=238$; $55 \%$ male; mean age 68.6 years) who were included in the analysis are shown in Table 2.

The proportion of patients receiving dopamine agonists and L-dopa by age group ( $<70$ years or $\geq 70$ years) and grade (II or III) is shown in Table 3. Whilst in younger patients (especially in grade II) dopamine agonists were more frequently used than L-dopa, the opposite was true in older patients. Therefore, the data indicate a general trend for neurologists to adhere to the guideline. Figure 1 illustrates the level of adherence to the four parameters; three of these parameters were only followed in about half of the patients. The recommendation to use dopamine agonists without L-dopa in patients $<70$ years old with lower grades of functional impairment (parameter 1, L-dopa-sparing approach) was observed in only $53 \%$ of cases $(n=34)$. Moreover, more than a third of these younger patients $(n=23 ; 36 \%)$ were already receiving L-dopa and 19\% $(n=12)$ were receiving L-dopa without a dopamine agonist. In patients $\geq 70$ years old in grade II (parameter 3) or III (parameter 4), recommendations to use L-dopa without dopamine agonists were also only partially

Table 2 Patient demographics $(n=320)$

\begin{tabular}{|c|c|}
\hline Age (years) ${ }^{*}$ & $67.2(9.6)$ \\
\hline Time since diagnosis (years) ${ }^{*}$ & $4.1(3.9)$ \\
\hline \multicolumn{2}{|l|}{ Hoehn and Yahr stage $\mathrm{e}^{\#}$} \\
\hline I & $82(27.0 \%)$ \\
\hline II & $144(47.4 \%)$ \\
\hline III & $65(21.4 \%)$ \\
\hline IV & $12(3.9 \%)$ \\
\hline V & $\mathrm{I}(0.3 \%)$ \\
\hline \multicolumn{2}{|l|}{ Home circumstances (multiple responses possible) } \\
\hline Lives with partner & $228(71.2 \%)$ \\
\hline Lives alone & $51(15.9 \%)$ \\
\hline Nursing home & $4(1.3 \%)$ \\
\hline Lives with family/friends & $27(8.4 \%)$ \\
\hline \multicolumn{2}{|l|}{ Employment status } \\
\hline Full time employment & $39(12.2 \%)$ \\
\hline Part time employment & $14(4.4 \%)$ \\
\hline Unemployed & $8(2.5 \%)$ \\
\hline Retired & 239 (74.7\%) \\
\hline Homemaker & $19(5.9 \%)$ \\
\hline Caregiver required - professional or informal & $182(56.9 \%)$ \\
\hline Hospitalized due to Parkinson's disease & $74(24.1 \%)$ \\
\hline
\end{tabular}

Table 3 Treatment received by patients $(n=320)$ divided into those aged $<70$ years or $\geq 70$ years, and grade II or grade III of functional impairment

\begin{tabular}{lll}
\hline & Grade II & Grade III \\
\cline { 2 - 3 } & $\begin{array}{l}\text { Patients aged }<70 \text { years } \\
(\mathrm{n}=64)\end{array}$ & $\begin{array}{l}\text { Patients aged }<70 \text { years } \\
(\mathrm{n}=127)\end{array}$ \\
\hline DA monotherapy & $27(42.2 \%)$ & $24(18.9 \%)$ \\
DA, no L-dopa & $34(53.1 \%)$ & $4 I(32.3 \%)$ \\
DA (overall) & $45(70.3 \%)$ & $107(84.3 \%)$ \\
L-dopa (overall) & $23(35.9 \%)$ & $81(63.8 \%)$ \\
L-dopa + DA & II (I7.2\%) & $66(52.0 \%)$ \\
L-dopa, no DA & $12(18.8 \%)$ & $15(11.8 \%)$ \\
\hline & Patients aged $\geq 70$ years & Patients aged $\geq 70$ years \\
& $(\mathrm{n}=18)$ & $(\mathrm{n}=1 \mathrm{II})$ \\
\hline L-dopa monotherapy & $4(22.2 \%)$ & $28(25.2 \%)$ \\
L-dopa, no DA & $9(50.0 \%)$ & $58(52.3 \%)$ \\
DA (overall) & $7(38.9 \%)$ & $49(44.1 \%)$ \\
L-dopa (overall) & $14(77.8 \%)$ & $102(91.9 \%)$ \\
DA, no L-dopa & $2(\mathrm{II.1 \% )}$ & $5(4.5 \%)$ \\
\hline Abbreviation DA, &
\end{tabular}

Abbreviation: DA, dopamine agonist.

adhered to $(n=9[50 \%]$ and $n=58$ [52\%], respectively). In contrast, the recommended use of dopamine agonists (mono or combination) in more functionally impaired patients aged $<70$ years (parameter 2 ) was observed in the majority of cases $(n=107 ; 84 \%)$.

A total of 137 of the 320 patients (43\%) were treated in accordance with the guidelines as stated by the neurologists. There were no statistically significant differences (Fisher's exact test) between the guideline and nonguideline groups of patients (Figure 1). However, more neurologists who claimed that their patients were in the "guideline group" adhered to parameter $1(n=16[66.7 \%]$ versus $n=18$ [45.0\%]). There was almost no difference between the two groups regarding adherence to parameter $2(n=48[85.7 \%]$ and $n=59[83.1 \%])$. The small sample size for parameter $3(n=18)$ precluded further statistical interpretation. For parameter 4, adherence was actually slightly higher in the nonguideline group $(n=36$; $55.4 \%)$ than in the guideline group $(n=22 ; 47.8 \%)$.

Treatment in the patient subgroups is summarized in Table 4. Symptom severity appeared to have an impact on the choice of therapy in less functionally impaired patients (grade II) in both age groups: in patients aged $<70$ years, L-dopa was less likely to be given to those with mild symptoms than those with more severe symptoms. Mild symptoms were also a predictor for the use of amantadine and monoamine oxidase (MAO)-B inhibitors in this age group. In patients aged $\geq 70$ years, mild symptoms were a predictor for dopamine agonist and amantadine use. In more functionally

Ab breviation: DA, dopamine agonist. 


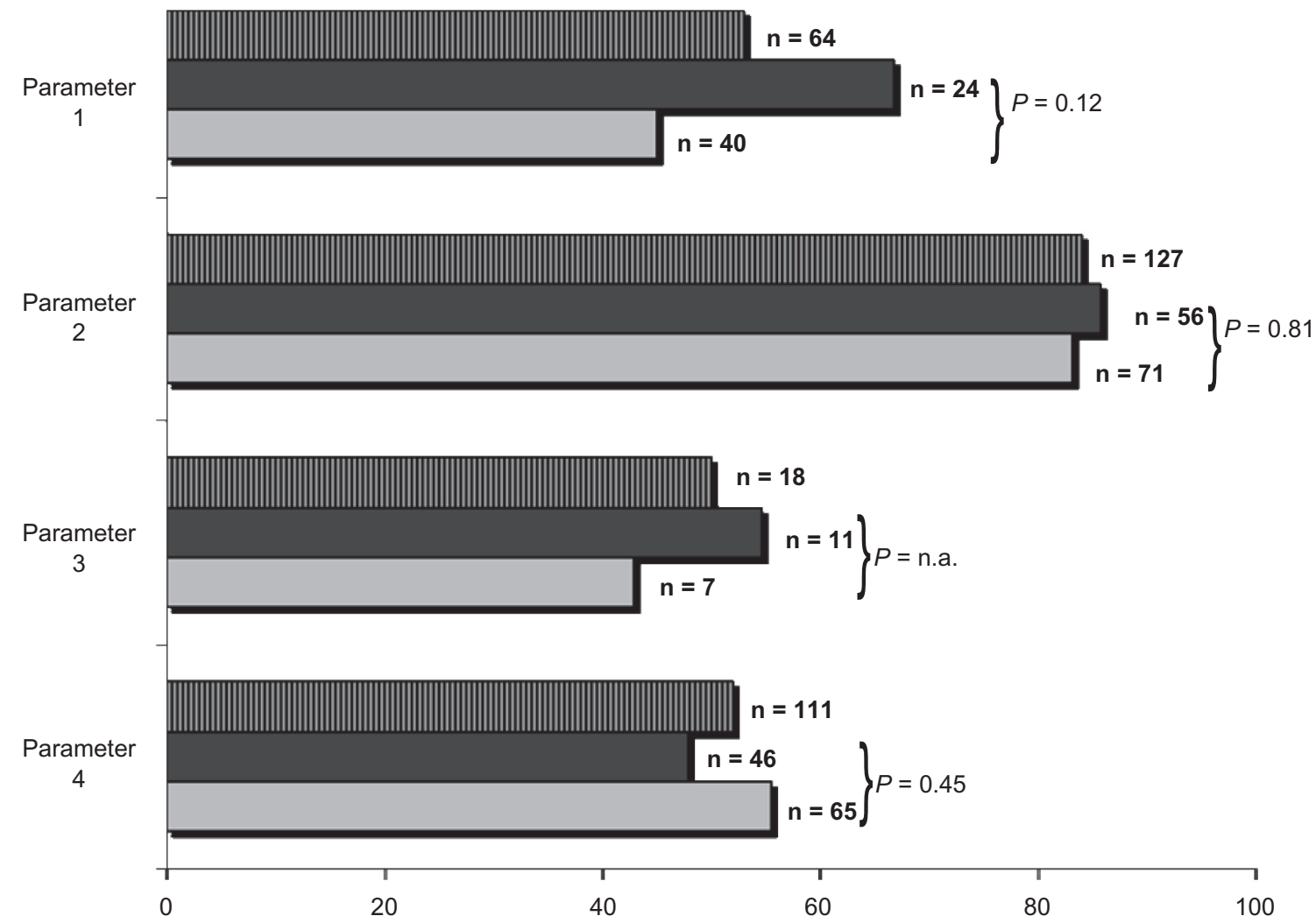

Percentage of patients treated in accordance with the rule

Overall adherence to national guideline

Guideline group

Nonguideline group

Figure I Level of adherence to national guideline. Overall adherence and adherence in neurologists who state that they follow the guideline ("guideline group") and those who do not state that they follow the guideline ("nonguideline group").

Notes: Parameter I. Patients $<70$ years, grade II $(n=64)$ : use of dopamine agonist without L-dopa. Parameter 2 . Patients $<70$ years, grade III ( $n=$ I 27$)$ : use of any dopamine agonists as mono or combination therapy. Parameter 3 . Patients $\geq 70$ years, grade II $(n=18)$ : use of L-dopa without dopamine agonists. Parameter 4 . Patients $\geq 70$ years, grade III $(\mathrm{n}=\mathrm{III})$ : use of L-dopa without dopamine agonists.

impaired patients (grade III), use of L-dopa plus dopamine agonist combination increased with time since diagnosis in those aged $<70$ years, but not in those aged $\geq 70$ years. The presence of cognitive impairment, however, did not have a marked effect on treatment decisions.

\section{Discussion}

Our results showed that neurologists in Germany use dopamine agonists and L-dopa differently in different patient populations, with treatment being dominated by dopamine agonists in younger patients and L-dopa in older patients. This is an initial indicator of a general adherence to the national guideline.

However, if the guideline is translated into strict parameters, as in the current study, it is apparent that neurologists do not adhere well to recommendations on monotherapy, regardless of the patient's age and grade of functional impairment. For example, only around half of patients aged
$<70$ years in H\&Y stage I received dopamine agonists without L-dopa and, surprisingly, more than a third were already receiving L-dopa. As patients with mild symptoms were less likely to receive L-dopa than those with more severe symptoms, symptom severity might be one reason for early use of L-dopa. Other potential reasons may involve individual patient circumstances and financial considerations reinforced by changes in health reform since, in Germany, L-dopa is much cheaper than dopamine agonists. Mild symptoms in patients with a lower grade of functional impairment were a clear predictor for use of amantadine and the MAO-B inhibitor selegiline; these findings are in line with guideline recommendations. Use of the L-dopa plus dopamine agonist combination increased with disease duration and grade of functional impairment, most notably in younger patients. This suggests that physicians try to adhere to the parameter of an L-dopa-sparing approach in younger patients for as long as possible. In patients aged $\geq 70$ years, 
Table 4 Percentage use of L-dopa, dopamine agonists, amantadine, and MAO-B inhibitors in patient subgroups $(n=320)$

\begin{tabular}{|c|c|c|c|c|c|c|}
\hline & & $\begin{array}{l}\text { Any } \\
\text { dopamine } \\
\text { agonist }\end{array}$ & $\begin{array}{l}\text { Dopamine } \\
\text { agonist + } \\
\text { L-dopa }\end{array}$ & L-dopa & Amantadine & $\begin{array}{l}\text { MAO-B } \\
\text { inhibitor }\end{array}$ \\
\hline \multicolumn{7}{|c|}{ Symptom severity - mild symptoms } \\
\hline \multirow[t]{2}{*}{$<70$, grade II } & Yes $(n=46)$ & $\begin{array}{l}31 \\
(67.4 \%)\end{array}$ & $\begin{array}{l}6 \\
(13.0 \%)\end{array}$ & $\begin{array}{l}15 \\
(32.6 \%)\end{array}$ & $\begin{array}{l}\text { II } \\
(23.9 \%)\end{array}$ & $\begin{array}{l}5 \\
(10.9 \%)\end{array}$ \\
\hline & No $(n=18)$ & $\begin{array}{l}14 \\
(77.8 \%)\end{array}$ & $\begin{array}{l}5 \\
(27.8 \%)\end{array}$ & $\begin{array}{l}8 \\
\text { (44.4\%) }\end{array}$ & 0 & 0 \\
\hline \multirow[t]{2}{*}{$\geq 70$, grade II } & Yes $(n=12)$ & $\begin{array}{l}6 \\
(50.0 \%)\end{array}$ & $\begin{array}{l}4 \\
(33.3 \%)\end{array}$ & $\begin{array}{l}9 \\
\text { (75.0\%) }\end{array}$ & $\begin{array}{l}4 \\
(33.3 \%)\end{array}$ & $\begin{array}{l}\text { I } \\
(8.3 \%)\end{array}$ \\
\hline & No $(n=6)$ & $\begin{array}{l}\text { I } \\
\text { (16.7\%) }\end{array}$ & (16.7\%) & $\begin{array}{l}5 \\
(83.3 \%)\end{array}$ & 0 & $\begin{array}{l}\text { I } \\
(16.7 \%)\end{array}$ \\
\hline \multicolumn{7}{|c|}{ Disease duration - time since diagnosis } \\
\hline \multirow[t]{2}{*}{$<70$, grade III } & $\begin{array}{l}<5 \text { years } \\
(n=84)\end{array}$ & $\begin{array}{l}71 \\
(84.5 \%)\end{array}$ & $\begin{array}{l}35 \\
(41.7 \%)\end{array}$ & $\begin{array}{l}44 \\
(52.4 \%)\end{array}$ & $\begin{array}{l}19 \\
(22.6 \%)\end{array}$ & $\begin{array}{l}12 \\
(14.3 \%)\end{array}$ \\
\hline & $\begin{array}{l}\geq 5 \text { years } \\
(n=43)\end{array}$ & $\begin{array}{l}36 \\
(83.7 \%)\end{array}$ & $\begin{array}{l}31 \\
(72.1 \%)\end{array}$ & $\begin{array}{l}37 \\
(86.0 \%)\end{array}$ & $\begin{array}{l}15 \\
(34.9 \%)\end{array}$ & $\begin{array}{l}10 \\
(23.3 \%)\end{array}$ \\
\hline \multirow[t]{2}{*}{$\geq 70$, grade III } & $\begin{array}{l}<5 \text { years } \\
(n=7 I)\end{array}$ & $\begin{array}{l}30 \\
(42.3 \%)\end{array}$ & $\begin{array}{l}25 \\
(35.2 \%)\end{array}$ & $\begin{array}{l}63 \\
(88.7 \%)\end{array}$ & $\begin{array}{l}12 \\
(16.9 \%)\end{array}$ & $\begin{array}{l}5 \\
(7.0 \%)\end{array}$ \\
\hline & $\begin{array}{l}\geq 5 \text { years } \\
(n=40)\end{array}$ & $\begin{array}{l}19 \\
(47.5 \%)\end{array}$ & $\begin{array}{l}19 \\
(47.5 \%)\end{array}$ & $\begin{array}{l}39 \\
(97.5 \%)\end{array}$ & $\begin{array}{l}15 \\
(37.5 \%)\end{array}$ & $\begin{array}{l}10 \\
(25.0 \%)\end{array}$ \\
\hline \multicolumn{7}{|c|}{ Cognitive impairment } \\
\hline \multirow[t]{2}{*}{$<70$, grade II } & Yes $(n=6)$ & $\begin{array}{l}4 \\
(66.7 \%)\end{array}$ & $\begin{array}{l}\text { I } \\
(16.7 \%)\end{array}$ & $\begin{array}{l}2 \\
(33.3 \%)\end{array}$ & $\begin{array}{l}\text { I } \\
(16.7 \%)\end{array}$ & 0 \\
\hline & No $(n=58)$ & $\begin{array}{l}41 \\
(70.7 \%)\end{array}$ & $\begin{array}{l}10 \\
(17.2 \%)\end{array}$ & $\begin{array}{l}21 \\
(36.2 \%)\end{array}$ & $\begin{array}{l}10 \\
(17.2 \%)\end{array}$ & $\begin{array}{l}5 \\
(8.6 \%)\end{array}$ \\
\hline \multirow[t]{2}{*}{$<70$, grade III } & Yes $(n=16)$ & $\begin{array}{l}13 \\
(81.3 \%)\end{array}$ & $\begin{array}{l}9 \\
(56.3 \%)\end{array}$ & $\begin{array}{l}11 \\
(68.8 \%)\end{array}$ & $\begin{array}{l}6 \\
(37.5 \%)\end{array}$ & $\begin{array}{l}\text { I } \\
(6.3 \%)\end{array}$ \\
\hline & No $(n=I I I)$ & $\begin{array}{l}94 \\
(84.7 \%)\end{array}$ & $\begin{array}{l}57 \\
(51.4 \%)\end{array}$ & $\begin{array}{l}70 \\
(63.1 \%)\end{array}$ & $\begin{array}{l}28 \\
(25.2 \%)\end{array}$ & $\begin{array}{l}21 \\
(18.9 \%)\end{array}$ \\
\hline \multirow[t]{2}{*}{$\geq 70$, grade II } & Yes $(n=3)$ & 0 & 0 & $\begin{array}{l}3 \\
(100 \%)\end{array}$ & 0 & 0 \\
\hline & No $(n=15)$ & $\begin{array}{l}7 \\
(46.7 \%)\end{array}$ & $\begin{array}{l}5 \\
(33.3 \%)\end{array}$ & $\begin{array}{l}11 \\
\text { (73.3\%) }\end{array}$ & $\begin{array}{l}4 \\
(26.7 \%)\end{array}$ & $\begin{array}{l}2 \\
(13.3 \%)\end{array}$ \\
\hline \multirow[t]{2}{*}{$\geq 70$, grade III } & Yes $(n=26)$ & $\begin{array}{l}11 \\
(42.3 \%)\end{array}$ & $\begin{array}{l}10 \\
(38.5 \%)\end{array}$ & $\begin{array}{l}23 \\
(88.5 \%)\end{array}$ & $\begin{array}{l}7 \\
(26.9 \%)\end{array}$ & $\begin{array}{l}3 \\
(11.5 \%)\end{array}$ \\
\hline & No $(n=85)$ & $\begin{array}{l}38 \\
(44.7 \%)\end{array}$ & $\begin{array}{l}34 \\
(40.0 \%)\end{array}$ & $\begin{array}{l}79 \\
(92.9 \%)\end{array}$ & $\begin{array}{l}20 \\
(23.5 \%)\end{array}$ & $\begin{array}{l}12 \\
(14.1 \%)\end{array}$ \\
\hline
\end{tabular}

the level of adherence to L-dopa without dopamine agonists was similar in grades II and III, with only limited agreement with the guideline in both cases. Combination therapy with L-dopa plus dopamine agonists increased slightly with longer disease duration and mild symptoms, which might partly explain nonadherence to the recommended monotherapy in older patients. The small number of patients aged $\geq 70$ years in grade II, as would be expected in Parkinson's disease, means that no firm conclusions can be drawn for this patient subgroup.

When comparing agreement with the parameters according to claimed guideline adherence, the differences did not achieve statistical significance. It therefore cannot be concluded that neurologists who claimed to follow the guideline did indeed follow it more strictly.
As the derivation of statistically testable parameters from any guideline recommendation is not straightforward, there may be a number of methodological reasons that influence the low level of agreement between the physician's treatment choice and the guideline. One possible reason is that the parameters cannot take into account individualized therapy based on patient characteristics as is recommended in the guideline. The different possible definitions of key variables are another potential problem. Initiation with and maintenance of monotherapy for as long as possible is one of the core recommendations. When translating the term "monotherapy" directly from the guideline, it is naturally linked to the L-dopa sparing approach in younger patients or the reluctant use of dopamine agonists in older or comorbid patients. However, we chose the more precise 
variables "dopamine agonist without L-dopa" and "L-dopa without dopamine agonist" to investigate accordance with the guideline.

Another factor that should be taken into account is that we divided the patients according to physician-rated grades of functional impairment based on H\&Y stages and L-dopa-associated motor complications, whilst the guideline does not. In particular, if maintenance of monotherapy for as long as possible is recommended, patients' level of functional impairment must be taken into account when translating the guideline recommendations into explicit parameters since progression across H\&Y stages is closely related to the duration of disease. ${ }^{22}$ Our analyses revealed that monotherapy was only partly followed by neurologists, independently of H\&Y stage. In general, and particularly when giving advice on monotherapy, the guideline should be more precise in terms of functional impairment.

In the analyses, we used data from a nationwide study aimed at obtaining as representative a sample of reallife Parkinson's disease patients in Germany as possible. Consequently neurologists were the focus, most of whom were office-based, as the majority of Parkinson's disease patients in Germany are treated in this setting. ${ }^{2}$ However, as prescription patterns may change if patients are treated by general practitioners or in outpatient clinics, ${ }^{23,24}$ it might be of interest to investigate guideline adherence in these settings, as well as in more severely ill patients at a later H\&Y stage or those treated as in-patients. In contrast to the results of some other studies in which the patient population was restricted, for example, to members of a support group, ${ }^{23}$ we used data from outpatients typical of those treated in everyday clinical practice. Nevertheless, there may have been an inherent selection bias amongst the neurologists who took part in the study, as only those who were able to provide the necessary information within the required time frame were selected.

The 10-13 months between publication of the guideline and performance of the survey should have allowed sufficient time to reflect the impact on clinical practice. Indeed, all physicians in the survey reported that they were aware of the content of the guideline. It is worthy of consideration that Parkinson's disease guidelines are based on evidence-based medicine and, as guidelines take around two years to develop, this evidence may itself be outdated by the time the guidelines are published. ${ }^{25}$ Many practicing physicians would therefore have also already been exposed to the evidence base during this intervening period. We presume that the physicians were, as they stated, aware of current treatment practices reviewed in the guidelines and that this survey can therefore be considered of relevance.

We investigated adherence to the first guideline that was issued in Germany in 2003. Updates of the guideline were published in 2005 and $2008,{ }^{26}$ and it is possible that the neurologists' awareness of treatment guidelines might have subsequently changed. Increasing concerns regarding adverse events associated with dopamine agonists, including daytime somnolence, leg edema, impulse control disorders, and valvular heart conditions ${ }^{27}$ may, for example, have influenced clinical practice since our survey was conducted in 2004. The current guidelines from 2008, however, still follow the same core treatment recommendations, albeit being more restrictive in the use of ergot dopamine agonists.

Findings from a study to assess German neurologists' awareness of the existence of the national guideline were published in 2005. ${ }^{13}$ This cross-sectional questionnaire was carried out using 181 neurologists in private practice. Surprisingly, only about half of the neurologists claimed to be aware of the guideline. Of these, $60 \%$ rated the guideline positively, although 53\% reported having problems using it in their general practice. This suggests that implementation strategies may be necessary to improve neurologists' knowledge and use of the guideline. A study into the attitudes and barriers to the national guideline in Germany indicated that lack of time and an inability to reconcile patient preferences with guideline recommendations were also important reasons for nonadherence. ${ }^{14}$ Previous researchers have shown that implementation of clinical guidelines is associated with a wide range of problems, ${ }^{28}$ although their adoption can help to improve the quality of care..$^{29,30}$ There is, however, a paucity of data on how guideline adherence influences the patient's outcome.

In conclusion, our study of German neurologists can be regarded as a pilot approach to translating a clinical guideline into distinctive parameters to evaluate guideline adherence of neurologists treating patients with Parkinson's disease. The findings revealed that recommendations were only partially followed. Further research is needed into the reasons for nonadherence and the impact of guideline adherence on therapeutic outcomes.

\section{Acknowledgments}

This study was supported by an unrestricted grant from Solvay Pharmaceuticals GmbH, Hannover, Germany, as part of a research project on the management of Parkinson's disease in Germany conducted at the Institute of Clinical Pharmacology, Charité University of Medicine, Berlin. 


\section{Disclosure}

Two of the authors were paid employees of Solvay Pharmaceuticals GmbH. None of the authors of this article have any other declarable conflict of interest.

\section{References}

1. Rascol O, Goetz C, Koller W, Poewe W, Sampaio C. Treatment interventions for Parkinson's disease: an evidence based assessment. Lancet. 2002;359:1589-1598

2. Wojtecki L, Südmeyer M, Schnitzler A. The current treatment of Parkinson's disease. Dtsch Arztebl. 2007;104:A2513-2522.

3. Damiano AM, McGrath MM, Willian MK, et al. Evaluation of a measurement strategy for Parkinson's disease: assessing patient healthrelated quality of life. Qual Life Res. 2000;9:87-100.

4. Dodel RC, Singer MS, Köhne-Volland R, et al. The economic impact of Parkinson's disease. An estimation based on a 3-month prospective analysis. Pharmacoeconomics. 1998;14:299-312.

5. Dodel RC, Berger K, Oertel WH. Health-related quality-of-life and healthcare utilisation in patients with Parkinson's disease: impact of motor fluctuations and dyskinesias. Pharmacoeconomics. 2001;19: 1013-1038.

6. Dowding $\mathrm{CH}$, Shenton CL, Salek SS. A review of the health-related quality of life and economic impact of Parkinson's disease. Drugs Aging. 2006;23:693-721.

7. Eggert K, Deuschl G, Gasser T, et al. Leitlinie Parkinson-Syndrome, 2 Ausg. Stuttgart, Thieme, 2005.

8. Klinische "Leitlinien" der deutschen Gesellschaft für Neurologie. Leitlinie für Diagnostik und Therapie in der Neurologie. Stuttgart, Germany: Thieme; 2003.

9. Oertel WH, Quinn N. Parkinsonism. In: Brandt T, Diener HC, Caplan LR, editors. Neurological Disorders: Course and Treatment. San Diego: Academic Press, 2002;1021-1079.

10. Olanow CW, Watts RL, Koller WC. An algorithm (decision tree) for the management of Parkinson's disease: treatment guidelines. Mov Disord. 2001;56:S1-S88.

11. Parkinson's Disease Consensus Working Group (PDCWG). Guidelines for the management of Parkinson's disease. Hosp Med. 1998;59: 469-480.

12. GKV-Modernisierungsgesetz. Bundesgesetzblatt Jahrgang 2003 Teil I No. 55, ausgegeben zu Bonn am 19. November 2003. Gesetz zur Modernisierung der gesetzlichen Krankenversicherung (GKVModernisierungsgesetz - GMG); vom 14. November 2003.

13. Eggert K, Larisch A, Dodel R, Bormann C, Oertel WH. Awareness and knowledge of the clinical practice guideline on Parkinson's disease among German neurologists. Eur Neurol. 2009;61:216-222.

14. Larisch A, Oertel WH, Eggert K. Attitudes and barriers to clinical practice guidelines in general and to the guideline on Parkinson's disease. A National Survey of German neurologists in private practice. J Neurol. 2009;256:1681-1688.
15. Askmark H, Antonov K, Aquilonius SM. The increased utilisation of dopamine agonists and the introduction of COMT inhibitors have not reduced levodopa consumption - a nation-wide perspective in Sweden. Parkinsonism Relat Disord. 2003;9:271-276.

16. Leoni O, Martignoni E, Cosentino M, et al. Drug prescribing patterns in Parkinson's disease: a pharmacoepidemiological survey in a cohort of ambulatory patients. Pharmacoepidemiol Drug Saf. 2002;11: 149-157.

17. Anderson P, Benford M, Harris N, Karavali M, Piercy J. Real-world physician and patient behaviour across countries: Disease-Specific Programmes - a means to understand. Curr Med Res Opin. 2008;24: 3063-3072.

18. http://www.esomar.org/uploads/pdf/professional-standards/ ICCESOMAR_Code_English.pdf

19. Hughes AJ, Daniel SE, Kilford L, Lees AJ. Accuracy of clinical diagnosis of idiopathic Parkinson's disease: a clinico-pathological study of 100 cases. J Neurol Neurosurg Psychiatry. 1992;55: 181-184.

20. Meara J, Bhowmick BL, Hobson P. Accuracy of diagnosis in patients with presumed Parkinson's disease. Age Ageing. 1999;28:99-102.

21. Marsden CD, Parkes JD. Success and problems of long-term levodopa therapy in Parkinson's disease. Lancet. 1977;1:345-349.

22. Alves G, Wentzel-Larsen T, Aarsland D, Larsen JP. Progression of motor impairment and disability in Parkinson disease: a populationbased study. Neurology. 2005;65:1436-1441.

23. Möller JC, Körner Y, Dodel RC, et al. Pharmacotherapy of Parkinson's disease in Germany. J Neurol. 2005;252:926-935.

24. Müller T, Voss B, Hellwig K, Josef Stein F, Schulte T, Przuntek H. Treatment benefit and daily drug costs associated with treating Parkinson's disease in a Parkinson's disease clinic. CNS Drugs. 2004; 18:105-11.

25. Yamamoto M. Practice guidelines for Parkinson's disease. Parkinsonism Rel Disord. 2003;9:S111-S115.

26. Klinische "Leitlinien" der deutschen Gesellschaft für Neurologie. Leitlinie für Diagnostik und Therapie in der Neurologie. Stuttgart: Thieme, 2008.

27. Antonini A, Tolosa E, Mizuno Y, Yamamoto M, Poewe WH. A reassessment of risks and benefits of dopamine agonists in Parkinson's disease. Lancet Neurol. 2009;8:929-937.

28. Cabana MD, Rand CS, Powe NR, et al. Why don't physicians follow clinical practice guidelines? A framework for improvement. JAMA. 1999;282:1458-1465.

29. Grimshaw JM, Russell IT. Effect of clinical guidelines on medical practice: a systematic review of rigorous evaluations. Lancet. 1993;342: 1317-1322.

30. Grimshaw JM, Eccles M, Thomas R, et al. Toward evidence-based quality improvement. Evidence (and its limitations) of the effectiveness of guideline dissemination and implementation strategies 1966-1998. J Gen Intern Med. 2006;21 Suppl 2:S14-S20.
Neuropsychiatric Disease and Treatment

\section{Publish your work in this journal}

Neuropsychiatric Disease and Treatment is an international, peerreviewed journal of clinical therapeutics and pharmacology focusing on concise rapid reporting of clinical or pre-clinical studies on a range of neuropsychiatric and neurological disorders. This journal is indexed on PubMed Central, the 'PsycINFO' database and CAS, and is the official

\section{Dovepress}

journal of The International Neuropsychiatric Association (INA). The manuscript management system is completely online and includes a very quick and fair peer-review system, which is all easy to use. Visit $\mathrm{http}: / /$ www.dovepress.com/testimonials.php to read real quotes from published authors. 